\title{
The Environmental Liability Directive, the Water Framework Directive and the Definition of 'Water Damage'
}

Environmental Law Review 2018, Vol. 20(3) 15I-162 (C) The Author(s) 2018

Article reuse guidelines: sagepub.com/journals-permissions DOI: $10.1|77 /| 46|4529| 87898 \mid 4$ journals.sagepub.com/home/elj

\author{
Henrik Josefsson \\ Department of Law, Uppsala University, Uppsala, Sweden
}

\begin{abstract}
The Environmental Liability Directive (ELD) focuses on remediating environmental damage. To assess environmental damage it uses existing assessment systems, and the constructs that are at the centre of these systems. One of these is 'ecological status' in the context of the Water Framework Directive (WFD). The ELD refers to the WFD with respect to what 'water damage' concerns, without specifying what it means and it offers no threshold for when deterioration is significant enough to count as 'water damage'. A definition of 'water damage' is developed, based on the European Court of Justice's latest rulings, which clarify when the deterioration of a body of water is so significant that it passes from 'deterioration' under the WFD, to 'water damage' under the ELD.
\end{abstract}

\section{Keywords}

Environmental Liability Directive, environmental damage, Water Framework Directive, water damage

\section{Introduction}

The Environmental Liability Directive ${ }^{1}$ (ELD) provides a public law system that aims to ensure that polluters restore environments that they have damaged. One of the noteworthy elements of the ELD is that liability applies to the environment that has been damaged and is not conditional on whether the area damaged is someone's property. The ELD defines what 'environment' refers to by defining 'environmental damage' and it refers to protected species and habitats, in keeping with the Habitats Directive ${ }^{2}$ (HD), water

1. Directive 2004/35/CE of the European Parliament and of the Council of 21 April 2004 on environmental liability regarding the prevention and remedying of environmental damage.

2. Council Directive 92/43/EEC of 21 May 1992 on the conservation of natural habitats and of wild fauna and flora.

Corresponding author:

Henrik Josefsson, Department of Law, Uppsala University, Uppsala 75I20, Sweden.

Email: henrik.josefsson@jur.uu.se 
(based on the $\mathrm{WFD}^{3}$ and the Marine Strategy Directive ${ }^{4}$ ), and land (soil). ${ }^{5}$ The ELD's recital 5 emphasises the importance of constructs derived from Community legislation having the same definitions, based on the same criteria, to allow for a coherent application of these constructs. This is an advantage for the ELD, as it can build its assessment of the environment on data and ECJ rulings found under other Community legislation and avoid the problem of inadequate references for determining environmental damage. However, for the HD and WFD assessment systems to conform to the ELD, and to be used to decide when environmental damage has occurred, it is necessary to determine what the deterioration/effect concerns, and when significant adverse effects have occurred. ${ }^{6}$ For protected species and natural habitats, ELD Annex I has requirements for determining when an effect is 'significant', and Annex II (1) sets out a common framework to choose the most appropriate measures to remedy damage to water, protected species, and natural habitats. What is missing is an Annex that describes when damage to water is 'significant'. ${ }^{7}$ In analyses of the ELD many discussions take place (for example, about the difference between land and habitat/species damage or the ELD's compensation scheme) but the meaning of 'water damage' is not discussed. ${ }^{8}$

The definition of 'water' in the ELD references the WFD and the ecological, chemical or quantitative status or the ecological potential of bodies of water, ${ }^{9}$ or to the environmental status of the marine waters concerned, according to the Marine Strategy Framework Directive. ${ }^{10}$ I will focus on the interaction between the ELD and the WFD and try to define 'water', especially what it applies to and when the deterioration of a body of water is so significant according to the WFD, that it has become 'water damage' according to the ELD. The aim is to give the ELD its missing Annex, at least regarding the 'ecological status' of bodies of water.

The article first describes the ELD and the construct of 'water damage' and then describes WFD and the elements to which the ELD construct of 'water damage' refers. 'Water damage' and its significant threshold is then defined.

\section{The Environmental Liability Directive}

The ELD concerns the prevention and remedying of environmental damage, and it has been the subject of both discussion and criticism. ${ }^{11}$ For example, it has been criticised for not acknowledging that some of the

3. Directive 2000/60/EC of the European Parliament and of the Council of 23 October 2000 establishing a framework for Community action in the field of water policy.

4. Directive 2008/56/EC of the European Parliament and of the Council of 17 June 2008 establishing a framework for community action in the field of marine environmental policy.

5. ELD, Art. 2(12).

6. Ibid. Art. 2(1)(b)(i).

7. There is no such Annex connected to 'land'.

8. See N. de Sadeleer, 'The Birds, Habitats, and Environmental Liability Directives to the Rescue of Wildlife Under Threat' in The Yearbook of European Environmental Law (Oxford University Press 2007); G. Winter, J.H. Jans, R. Macrory, L. Krämer, 'Weighing up the EC Environmental Liability Directive' (2008) 20 Journal of Environmental Law 163; G.M. van den Broek, 'Environmental Liability and Nature Protection Areas: Will the EU Environmental Liability Directive Actually Lead to the Restoration of Damaged Natural Resources?' (2009) 5(1) Utrecht Law Review 117-131; L. Bergkamp and B. Goldsmith (eds), The EU Environmental Liability Directive: A Commentary (Oxford: Oxford University Press, 2013); C.T. Reid and W. Nsoh, The Privatisation of Biodiversity? (Cheltenham: Edward Elgar Publishing, 2016).

9. ELD, Art. 2(1)(b)(i).

10. Ibid. Art. 2(1)(b)(ii).

11. G. Winter and others, 'Weighing up the EC Environmental Liability Directive' (2008) 20 Journal of Environmental Law 163; Lucas Bergkamp and Barbara Goldsmith (eds), The EU Environmental Liability Directive: A Commentary (Oxford University Press 2013). 
basic legal terminology and classifications being used often have divergent resonances in different jurisdictions. ${ }^{12}$ Two other examples, that do not offer clear guidelines to define when environmental damage take place for both species and habitats ${ }^{13}$ and, more so, for water. ${ }^{14}$

The ELD focuses on the prevention and remediation of environmental damage, and operators are obliged to prevent and restore environmental damage for which they are responsible. ${ }^{15}$ When damage has occurred, the aim of the ELD is to restore baseline conditions, that is, the conditions that would have existed, had the environmental damage not occurred. ${ }^{16}$ To ensure this, the ELD requires public authorities to ensure that the polluter restores the damaged environment to baseline conditions. ${ }^{17}$ The competent authorities may also order the polluter to restore the damaged environment. ${ }^{18}$ If the operator cannot meet the obligation to restore the environment, the competent authorities may undertake the measures ${ }^{19}$ and they must recover the costs related to the preventive or remedial actions taken to achieve baseline conditions. ${ }^{20}$ Even so, the operator's obligation to bear these costs is not absolute, as Member States may allow operators who are not at fault or negligent not to bear the costs of remedial measures. ${ }^{21}$

The ELD has two liability schemes. The first provides a strict liability regime for environmental damage caused by any of the occupational activities listed in its Annex III. ${ }^{22}$ The second offers a fault liability scheme concerning damage to HD protected species and natural habitats. ${ }^{23}$ For 'water damage', the strict liability regime is applicable and in Annex III, there are several activities that are connected to the aquatic environment, for example the discharge of pollutants into surface water or groundwater, water abstraction and impoundment of water subject to prior authorisation in pursuance of the WFD. ${ }^{24}$

Although many of the ELD constructs and definitions echo the HD and WFD, it offers a more explicit regulatory framework for resolving 'water damage' and water must be restored to its baseline condition by way of primary, complementary, and compensatory remediation. ${ }^{25}$ 'Primary' remediation is the main measure; 'complementary' remediation is used to when primary remediation does not fully achieve baseline conditions. The purpose of complementary remediation is to achieve baseline conditions through other measures at an alternative site, compared to the affected site, if appropriate. Where possible and appropriate, the alternative site should be geographically linked to the damaged site, considering the interests of the affected population. Compensatory remediation is undertaken to compensate for the interim loss and should begin on the date the damage occurs. This consists of additional improvements to the impacted water, either at the damaged site or at an alternative site. Furthermore, complementary and compensatory remedial measures should be so designed that they support additional elements, to reflect the time required for measures to take effect; for example, the longer the period until baseline conditions are reached, the greater

12. See Winter et al., above n. 8 .

13. L. Bergkamp and A. van Bergeijk, 'Scope of the ELD Regime' in Lucas Bergkamp and Barbara Goldsmith (eds), The EU Environmental Liability Directive: A Commentary (Oxford: Oxford University Press, 2013) 58-61.

14. S. Cassotta, Environmental Damage Liability Problems in a Multilevel Context: The Case of the Environmental Liability Directive (Alphen aan den Rijn: Wolters Kluwer, 2012) 215.

15. ELD, Arts 1, 2, 5, 6 .

16. Ibid. Art. 2(14).

17. Ibid. Art. 6.

18. Ibid. Art. 6(2).

19. Ibid. Art. 6(3).

20. Ibid. Art. 8(1)(2), se also recital 18.

21. Ibid. Art. 8(4).

22. Ibid. Art. 3(1)(a).

23. Ibid. Art. 3(1)(b). See also WFD, Art. 11(3)(g)(h).

24. See WFD Art. 11(3)(g)(h)(e). Several other activities are found in Annex III that could result in 'water damage'.

25. See ELD, Annex II. 
the number of compensatory remedial measures that should be undertaken. ${ }^{26}$ The ELD scheme to achieve baseline conditions complements the WFD by specifying that all practical measures should be used to restore a deteriorating area of water to its status prior to the damage, ${ }^{27}$ by having a system in place to accomplish this, and by specifying how remediation should be conducted when recovery is impossible or will take a long time. ${ }^{28}$

It is worth noting that both complementary and compensatory remediation at a site other than the damaged area is possible. This may be compared to the WFD, where water deterioration results in the obligation to prevent further deterioration, and to take all practicable measures to remediate the effects to the body of water, and not an alternative body of water. ${ }^{29}$ According to the WFD, a body of water must be restored. For the ELD, the space of regulation is the damaged area and if primary remediation does not achieve baseline conditions or interim losses occur, complementary and/or compensatory remedial measures must be implemented, even if this applies to areas outside the damaged area. Thus, the space for remediating 'water damage' is different than the space of regulation that is intended to support 'good status' ${ }^{30}$

\section{The definition of water damage}

The ELD divides the environment into three categories: protected species and natural habitats (in keeping with the HD), ${ }^{31}$ water (marine and aquatic) and land (soil). ${ }^{32}$ 'Damage to the environment' means a measurable, adverse change in a natural resource (that is, protected species and natural habitats, water, and land) or the measurable impairment of a natural resource service that may occur directly or indirectly. ${ }^{33}$ 'Services and natural resource services' refer to the functions performed by a natural resource for the benefit of another natural resource or the public. ${ }^{34}$ Except for its 'natural resource service' construct, the ELD uses WFD constructs to measure when water damage has occurred.

The construct of 'water damage' is established by combining the ELD and WFD and it refers to significant adverse effects on the ecological, chemical, and/or quantitative status and/or ecological potential of a the waters concerned. ${ }^{35}$ 'Waters' means all water covered by the WFD, based on its definition of a body of water. ${ }^{36,37}$ 'Damage' means a measurable, adverse change in the 'ecological status' of a body of water, which may also be assessed in terms of measurable impairment to a natural resource service. ${ }^{38}$ Here, 'service' refers to activity such as that of species communities, which results in functions that are beneficial

26. Ibid., para. 1.2.3.

27. See WFD, art. 4(6)(d).

28. See ELD, Annex II.

29. E.g., see WFD art. 4 (6)(a)(c)(d).

30. H. Josefsson, 'Assessing Aquatic Spaces of Regulation: Key Issues and Solutions' (2014) 3 Nordic Environmental Law Journal 23.

31. For an analysis of the Habitats Directive and the ELD, see van den Broek, above n. 8.

32. ELD, Art. 2(12).

33. Ibid. Art. 2(2).

34. Ibid. Art. 2(13).

35. ELD, Art. 2(1)(b) and WFD, Art. 2(21), Annex V (1.1) (1.2).

36. See Bergkamp and van Bergeijk, above n. 13 at 66.

37. See WFD, Art. 2(5); Commission Staff Working Document, REFIT (Evaluation of the Environmental Liability Directive), Accompanying the document 'Report from the Commission to the European Parliament and to the Council pursuant to Article 18(2) of Directive 2004/35/EC on environmental liability with regard to the prevention and remedying of environmental damage' SWD (2016) 121 final, 52.

38. WFD, Art. 2(2)(12). 
to other natural resources or the public. ${ }^{39}$ The ELD does not define what 'function' includes with reference to 'waters'. The WFD's definition of 'ecological status' refers to the quality of the structure and functioning of aquatic ecosystems associated with surface waters, classified in accordance with Annex V. ${ }^{40}$ As the definition of 'water damage' is based on the WFD definition of 'ecological status' it is reasonable to conclude that the construct 'function', with regard to 'waters' in the ELD, refers to the definition of 'functioning' ecosystems in the WFD. Functioning aquatic ecosystems in the WFD are assessed through the quality elements found in Annex V, foremost the biological quality elements.

\section{The water damage threshold}

Ecologically, a threshold is the limit at which certain processes may start changing dramatically. It may be understood legally as a limit that, when crossed, necessitates certain legal requirements, such as measures that neutralise the deterioration and/or achieve baseline conditions. The WFD objective of 'non-deterioration' and the ELD construct of 'water damage' represent such legal thresholds. Whereas the threshold for 'non-deterioration' was clarified by the ECJ in Weser, ${ }^{41}$ 'water damage' has not been similarly clarified. However, that damage to the environment has widespread effects was made clear in Case C-529/15, Folk, where the Advocate General and the ECJ concluded that damage arising from the 'normal' operation of an authorised activity may result in 'water damage' (especially if it occurred prior to the WFD). ${ }^{42}$ However, the case revolved around access to justice with regard to 'water damage'. The ECJ did, however, say that projects which have an adverse effect on 'water' must meet the conditions set out in Article 4(7) so they do not overstep the threshold of non-deterioration. Thereby, one way to determine when deterioration is significant is to determine when WFD Article 4(7) is not applicable to the adverse effects, which would also mean that a Member State is in breach of the WFD. ${ }^{43}$

The reference to Article 4(7) allows the ELD to determine when 'water damage' has not occurred. This is similar to the way in which ELD Annex I is constructed, which first describes which data should be used to determine significant adverse changes to protected species and natural habitats and then provides several examples of circumstances that do not have to be classified as significant (for example, negative variations that are smaller than normal natural fluctuations and damage from which the species or habitat in question will recover in a short time and without intervention). ${ }^{44}$ These examples speak of a low threshold for when the effects become significant. For example, negative variations that are larger than normal natural fluctuations could have a significant adverse effect on protected species and natural habitats.

\section{The Water Framework Directive}

The WFD provide the common principles and the overall framework for action and development of the general principles and structures for protection and sustainable water use. ${ }^{45}$ One of its purposes is to prevent and halt deterioration and to protect and enhance aquatic ecosystems. This is elaborated and conceptualised in Article 4, which contains the central environmental objectives and exemptions. Article 4(1)(a) imposes

39. Ibid. Art. 2(13).

40. Ibid. Art. 2(21).

41. See section 'The defintion of Ecological Status'.

42. Case C-529/15, Gert Folk [2017] EU: C:2017:419 at 32-33; Case C-529/15, Gert Folk, Opinion of Advocate General Bobek [2017] EU: C:2017:1 at 43 .

43. ELD, Art. 2(1)(b).

44. Ibid. Annex I.

45. WFD, Recital 18. 
an ambitious requirement on Member States and they are obligated to 'aim to achieve' good surface water status by the end of 2015,2021 or 2027, and prevent further deterioration of the status of all bodies of water. ${ }^{46}$ Whereas non-deterioration is a general objective, good surface water status comprises both 'good chemical status' and 'good ecological status'. The rest of this section describes the obligation of nondeterioration and the assessment system that make up the 'good ecological status' objective to explain (a) what the reference in the ELD includes ${ }^{47}$ and (b) specifies the threshold of non-deterioration as a reference for determining the 'significant adverse effect' threshold under the ELD. ${ }^{48}$

\section{The definition of ecological status}

Even if the definition of 'ecological status' concerns the establishment of 'good ecological status', it is interlinked with the other ecological objectives of the WFD - 'non-deterioration' and 'ecological potential'. It seems consistent to connect 'water damage' to the definition of 'ecological status' so it can be assessed consistently with the WFD. ${ }^{49}$

The WFD defines 'ecological status' as the expression of the quality of the structure and functioning of aquatic ecosystems associated with surface waters, classified in accordance with Annex V. ${ }^{50}$ Annex V's normative definitions are reduced to three groups of quality elements: biological, hydromorphological and physico-chemical. Generally, the biological quality elements (phytoplankton, macrophytes and phytobenthos, benthic invertebrate fauna and fish fauna) are considered the most important, as they are the main elements that indicate the status of the structure ${ }^{51}$ and functioning ${ }^{52}$ of a body of water. The intention is that the biological quality elements should be able to indicate the stresses and effects of human activities, thereby making it possible to determine how far from 'high ecological status' a body of water is. The definitions of 'good' and 'moderate' status is cross-referenced with 'high'; this establishes the expectations and conditions to which assessment, classification, and management must refer.

Hydromorphological quality elements are consistent with the biological quality elements at 'good ecological status', whereas the physico-chemical elements also require that temperature, oxygen balance, $\mathrm{pH}$, acid-neutralizing capacity and salinity do not reach levels outside the range established to ensure the functioning of type-specific ecosystems. If the physico-chemical elements have 'good' status and specific non-synthetic and synthetic pollutants are within their limit values, ${ }^{53}$ it is assumed that the aquatic ecosystems will not be affected to such extent that the biological quality elements cannot maintain themselves over the long term.

46. Ibid Art. 4(4), 4(4)(c).

47. ELD, Art. 2(1)(b)

48. Although effects on the chemical and quantitative status of a body of water/body of groundwater may result in 'water damage', I will not discuss these elements of the WFD. This is because the WFD presents these two aspects of water differently from the 'ecological status' objectives, which exceeds the scope of this article.

49. See H. Josefsson, 'Good Ecological Potential - A Credible Objective for Water Management?' (2016) 13 Journal for European Environmental and Planning Law 167-189; H. Josefsson, 'Ecological Status as a Legal Construct - Determining Its Legal and Ecological Meaning' (2015) 27 Journal of Environmental Law 231.

50. WFD, Art. 2(21).

51. Ecosystem 'structure' refers to composition, abundance, biomass, diversity, and sensitivity.

52. Ecosystem 'functioning' refers to activity such as decomposition or nutrient cycling, that may be coupled to indicators such as size (e.g. body size or body mass), reproduction, or development of a particular species or age structure on individual, population, and community bases.

53. See Directive 2008/105/EC of the European Parliament and of the Council of 16 December 2008 on environmental quality standards in the field of water policy, amending and subsequently repealing Council Directives 82/176/EEC, 83/513/EEC, 84/156/ EEC, 84/491/EEC, 86/280/EEC and amending Directive 2000/60/EC of the European Parliament and of the Council. 
Even if Annex V 1.2 is only a starting point for Member States and does not specify in detail the actual assessment and management of 'ecological status', it is the binding point of departure for the Member States as specification of the objectives to be achieved. ${ }^{54}$ It explains what the ecological objectives in Article 4 refer to and provides a certain flexibility regarding the diversity and uniqueness of aquatic ecosystems. As emphasised in the WFD preamble, there are diverse conditions and needs in the EU that need different solutions. $^{55}$

Compared to the specification of 'good ecological status', the non-deterioration obligation has no further specification in Annex V. That 'non-deterioration' still refers to the quality elements found is implicit, as the status of a body of water may be ascertained following an assessment based on Annex V. The generality of the obligation is restricted to bodies of water for which the 'ecological status' is known, as otherwise, an activity or project that might negatively affect the status cannot be evaluated. ${ }^{56}$ Thus, for the obligation to function properly, the relevant quality elements must have been assessed in accordance with the WFD Annex $\mathrm{V}$ and implemented in a river basin management plan. If these requirements have been met, the obligation of non-deterioration then applies. ${ }^{57}$

\section{The non-deterioration threshold}

The key question concerning 'water damage' is what counts as a significant adverse change in the 'ecological status' of a body of water. The WFD has its own threshold objective, 'non-deterioration' and in Case C-461/13, Weser, ${ }^{58}$ which concerned further deepening and developement of the river Weser to allow for larger vessels to reach ports of the river, the ECJ defined what counts as deterioration under the WFD. As 'water damage' and 'non-deterioration' are similar, in that both refer to a threshold situation where a certain amount of deterioration prompts certain legal responses and in the ELD, 'waters' is based on the WFD conception of 'ecological status', it seems reasonable to conclude that 'non-deterioration' and 'water damage' are interconnected and should be consistently interpreted.

In Weser, the ECJ stated that the WFD's non-deterioration threshold, is overstepped as soon as the status of at least one of the quality elements falls by one class, even if that does not result in a fall in the classification of the body of surface water as a whole. ${ }^{59}$ However, if the individual quality element is already in the lowest class, any deterioration constitutes a 'deterioration of the status' of the body of water as a whole. ${ }^{60}$ The ECJ definition of non-deterioration does not constitute significant deterioration in the sense intended by the ELD, ${ }^{61}$ so a 'deterioration' may have an adverse effect, but one which is not significant. ${ }^{62}$ A starting point for defining the ELD threshold is to identify whether, under the WFD, it is possible to establish when there is a significant adverse effect on a body of water, and not just a 'deterioration of the status'/'an adverse effect' of a body of water, as defined by the ECJ.

Under Article 4(7) of the ELD, WFD is a reference for when 'water damage' has not taken place. It would therefore seem plausible that a deterioration that cannot be included under Article 4(7) could result in 'water damage', which also constitutes a breach of the WFD non-deterioration obligation. The general

54. See Josefsson, 'Ecological Status' above n. 49.

55. WFD, Recital 13.

56. Even if a precautionary approach, regarding activities known to lead to the deterioration of the aquatic environment, should still be applied (see art. 191(2) TFEU and Water Framework Directive, recital 11)).

57. Case C-461/13, Bund für Umwelt und Naturschutz Deutschland [2015] EU: C:2015:433 at 42, 47.

58. Ibid.

59. Ibid. at 70 .

60. Ibid.

61. See C-529/15 Gert Folk above n. 42 at 36; C-529/15, Opinion of Advocate General Bobek, (n 42) at 37.

62. Compare with WFD art. 4(3) where a significant adverse effect is necessary for its application. 
requirement for applying Article 4(7) is that deterioration is the result of new modifications to the physical characteristics of surface water. ${ }^{63}$ If the deterioration is not new, the only options for exempting the activity are to classify the body of water as heavily modified or artificial, ${ }^{64}$ or to exempt it through Article 4(5) if the activity fulfils the criteria of these two articles. However, this only changes the elements of assessment and the positive objective of the body of water, not the deterioration threshold itself. ${ }^{65}$ The other requisites of Article 4(7) do not concern the ecological threshold of deterioration under the WFD, but instead apply social elements to determine when the exemption is applicable, such as overriding the public interest. Article 4(7) thereby has a limited scope as it only applies to new modifications to the physical characteristics of a body of water. Deterioration that follows because of other modifications may be classified as both 'water damage', according to ELD and deterioration, according to WFD. It is noteworthy that the only accepted reason for the deterioration from 'high' to 'good' ecological status is 'new, sustainable human development' and not overriding public interest.

Article 4(6) of the WFD, which exempts temporary deterioration from the non-deterioration prohibition, could also help to determine when a significant adverse effect occurs, even if it is not mentioned in the ELD. Temporary deterioration in 'ecological status' is allowed if this is the result of circumstances of natural origins or force majeure, which are exceptional or could not reasonably have been foreseen. There are several other conditions connected to this exemption, but it is vital that all practicable steps be taken to prevent further deterioration of impacted and adjacent bodies of water. The deterioration must be reviewed annually and the body of water should be restored to its status prior to the deterioration, as soon as reasonably possible. Article 4(6) is thereby constructed similarly to Article 4(7) but has one element which might indicate when deterioration is significant. When an unforeseeable accident occurs, all practicable steps must be taken to prevent further deterioration in status to avoid compromising the WFD objectives for other bodies of water unaffected by those circumstances. ${ }^{66}$ When deterioration compromises the achievement of the WFD objectives for other bodies of water, it would seem to be significant, since the exemption of Article 4(6) is not applicable. Since Article 4(7) does not apply to temporary deterioration, it would be a breach of the WFD if deterioration in one body of water compromises the achievement of the WFD objectives for others. Article 4(8) specifies that the actualisation of exemptions, referring to Article $4(3)(4)(5)(6)(7)$, should not compromise the achievement of the WFD environmental objectives in other bodies of water.

In Weser, the Advocate General discussed various theories of 'deterioration' and later chose to understand non-deterioration in terms of each quality element class. The ECJ and the Advocate General rejected the deterioration result when classifying a body of water into a lower class (the status classes theory). ${ }^{67}$ They rejected the 'classes' construct, because classification of a body of water follows the lowest value of the applicable elements, in conjunction with the 'one out, all out' rule, which would allow for deterioration of all elements with higher values. ${ }^{68}$ The choice was between two clear thresholds and the ECJ preferred the more stringent one. The less stringent threshold, the 'classes' construct, definitely seems significant. Since, an adverse effect on a body of water refers to the deterioration of a body of water, according to Weser, it would not be out of place to use the 'classes' construct as a reference for the 'water damage' threshold.

63. See Case C-346/14, Commission v Austria [2016] EU: C:2016:322.

64. WFD, Art. 4(3).

65. Ibid. Art. 4(5)(c).

66. Also see Art. 4(8).

67. See C-461/13 Bund für Umwelt und Naturschutz Deutschland above n. 57 at 59-70.

68. Ibid. at 66 . 


\section{A coherent definition of 'water damage'}

The WFD and the ELD define each other and the constructs of 'water damage', 'non-deterioration', and 'ecological status' are interlinked. The missing 'water' Annex of the ELD may be constructed if its main construct of 'water damage' is developed based on both the ELD and the WFD.

\section{The Definition}

In Article 2(1)(b)(i) 'water damage' is defined as damage that significantly and adversely affects the ecological, chemical, quantitative status or ecological potential, as defined in WFD. In Weser, the ECJ clarified that the WFD's assessment and monitoring regimes are important parts of the non-deterioration obligation, when it emphasised that deterioration is not a question of class, but that each quality element used to classify a body of water, in accordance with Annex V, is important when determining the 'ecological status' secured by non-deterioration. ${ }^{69}$ One of the outcomes of Weser is that not only did the ECJ define the assessment resolution on deterioration for the WFD, but it also defined the resolution of 'water damage' where the WFD is applicable. Therefore, the normative definitions of Annex V explain how aquatic biodiversity should be simplified and assessed under both the WFD and ELD.

It is worth noting that due to the links between the WFD and ELD, the ELD system of liability includes aquatic ecosystem structures and functioning. If the operations of an activity listed under Annex III have a significant adverse effect on the functioning of the ecosystem of a body of water, the party responsible may be responsible for restoring the ecosystem. In Case C 529/15, it appeared that fish fauna that could not maintain 'good ecological status' because of the water regime imposed by a hydropower station; achieving 'good' fish fauna status seemed to demand hydromorphological changes to the body of water. Under these conditions, necessary measures involve re-establishing the condition of the body of water before the water regime was altered by the hydropower station, to achieve baseline conditions and to ensure that the ecosystem of the body of water can resume functioning (for example by assessing through age the structure of the fish communities). The obligation to implement this type of measure depends on whether the threshold of 'water damage' is overstepped.

\section{The Threshold}

A clear threshold for 'water damage' is necessary for clarifying when measures must be implemented to achieve baseline conditions for bodies of water. This should include a clear differentiation from the threshold for 'non-deterioration'.

In Weser, the ECJ developed the non-deterioration threshold for bodies of water and the deterioration threshold is the status class change of a quality element used to assess a body of water. ${ }^{70}$ This means that Member States may, at their discretion, allow for deterioration in each class and, in some instances, apply various exemptions, ${ }^{71}$ which makes the threshold seem a reasonable baseline for the more ambitious objective of 'good ecological status'. If translating the systematisation of the non-deterioration threshold to 'water damage', a certain level of impact would be accepted before it became necessary to compensate for the impact.

If 'adverse change' refers to deterioration as defined in Weser ${ }^{72}$ deterioration corresponding to the 'classes' theory seems significant and still builds on the WFD conceptualization of 'non-deterioration'.

69. Ibid. at 70 .

70. See WFD Annex V 1.3.

71. See WFD Art. 4(6)(7).

72. See also C-529/15 Gert Folk, above n. 42 at 36. 
However, since in some instances the 'classes' construct is comparable to non-deterioration, when the poorest quality element drops one class, it seems reasonable to equate the construct of 'water damage' with the deterioration of each quality element by one class, in keeping with Annex V, for the deterioration to be significant. This would clearly differentiate 'non-deterioration' from 'water damage'.

If deterioration by a full class corresponds to 'water damage', two classes of bodies of water that may need a different threshold: bodies of water with high status and those with the lowest status. In Weser, the Advocate General observed that, concerning bodies of water in the lowest class, both the deterioration of the status of a body of water and the deterioration of one quality element exclude the lowest class from the scope of deterioration. ${ }^{73}$ At some level, the deterioration of a body of water in the lowest class must not only breach the WFD non-deterioration objective, but also count as water damage according to the ELD. The ELD threshold could refer to deterioration where all the quality elements of a body of water not having 'bad status' deteriorate by one class and the quality element with 'bad status' deteriorates measurably. If all the quality elements have 'bad status', then measurable deterioration of all the quality elements could equate to 'water damage'. This differs from the description in the WFD, where change in each quality element counts as deterioration. ${ }^{74}$ Still, it may be difficult to define the difference between the thresholds for 'non-deterioration' and 'water damage' for bodies of water where all the quality elements are in the lowest class. Here, it may be necessary to use nearby bodies of water as indicators of 'water damage' and when the objectives of these nearby bodies of water are compromised, according to the WFD, those directly affected by the deterioration reach the threshold of 'water damage'.

If the threshold developed for 'water damage' is accepted and 'water damage' occurs, and neighbouring bodies of water also deteriorate, but not to such an extent that the threshold of 'water damage' is overstepped, under what directive should this be managed? Since the ELD scheme for achieving baseline conditions is more advanced, the ELD framework seems more appropriate for remedying 'water damage' than the WFD. ${ }^{75}$

Also, not applying the ELD to managing the 'water damage' incident would seem to be a strange exception. It would be more consistent to suggest that 'water damage' deterioration be managed under the ELD to achieve baseline conditions, including other bodies of water where the deterioration is 'non-deterioration' only within the framework the WFD. Likewise, bodies of water where the 'nondeterioration' threshold is not overstepped by the 'water damage' incident, but some other WFD environmental objective is compromised should also be part of the 'water damage' area. This allows for consistency and a coherent approach to 'water damage' within river basins where there are both small and larger water areas.

Should bodies of water with 'high status' have a different threshold, compared to those with lower status? Only Article 4(7) requires them to receive greater protection from deterioration. In the WFD, only bodies of water from which drinking water is abstracted - not those with 'high status' - are required to ensure that there is necessary protection. ${ }^{76}$ Therefore, the WFD does not indicate that the construct of 'water damage' should be applied differently to 'high status' bodies of water, compared to those with lower status. Should bodies of water that hold drinking water have a different threshold for 'water damage'? The WFD does not indicate this; instead, these should be protected so that a 'water damage' incident becomes extremely unlikely.

73. Ibid. at 63; Case C-461/13, Bund für Umwelt und Naturschutz Deutschland, Opinion Advocate General Jääskinen [2014] EU: C:2014:2324 at 102 .

74. Gert Folk above n. 42 at 69.

75. See ELD, Annex II.

76. See WFD Art. 7(3). 
Applying these conceptualizations of 'water damage' and 'threshold' would give Member States an area of discretion in which to address deterioration of bodies of water according to the WFD; if deterioration is significant, they may then turn to the ELD framework. So, the analysis suggests that, under the ELD, 'water damage' is significant and results in measures for achieving baseline conditions under the following circumstances:

- When all the quality elements used to classify a body of water, according to Annex V, deteriorate by one class.

- When a body of water is affected by deterioration that results in a class change for the biological quality elements not in lowest class, and a measurable change in the quality element in a lowest class.

- When all the biological quality elements in a body of water are in a lowest class deteriorate measurably and the deterioration of that body of water compromises the achievement of WFD objectives for other bodies of water.

Overstepping any of these three thresholds for 'water damage' would risk an irreversible deterioration in the populations, communities, and taxa affected, and disturb the ecosystem functioning of the site. Using this type of threshold to determine compensation measures would treat the overarching construct of 'environmental damage' as a serious incident, while differentiating it from 'non-deterioration', which, because of its regulatory nature, should be more stringent. If these are not the circumstances surrounding the deterioration, there is no 'water damage' and measures to improve the status of the body of water should take place according to the WFD.

\section{Conclusion}

Despite EU efforts, for example, under the WFD and the HD, biodiversity continues to decline throughout the EU. ${ }^{77}$ Thresholds for deterioration are important to ensure that no further loss of biodiversity occurs. When the ECJ developed the threshold for 'non-deterioration', it provided an important reference for other similar deterioration thresholds, such as 'water damage' in the context of the ELD. ${ }^{78}$

The WFD and ELD have similar historical attributes, in that they both have a threshold objective and this was undefined by the legislator. Today, the WFD threshold for non-deterioration has been clarified by the ECJ, but the ELD threshold for 'water damage' remains unclarified. It has been noted in the doctrine ${ }^{79}$ that the Commission has stepped back from bringing cases before the ECJ within the context of the WFD and perhaps this reluctance has also affected the construct of 'water damage', as it stands without a proper definition.

In early assessment of the ELD, one conclusion was that its real implications would be unknown for some years both in terms of its impact on national legal systems and its contribution to the protection of the environment in practical terms. ${ }^{80}$ This assessment still stands if the ELD is understood in isolation from the

77. See 'Communication from the Commission to the European Parliament, The Council, the Economic and Social Committee and the Committee of the Regions, Our Life Insurance, Our Natural Capital: An EU Biodiversity Strategy to 2020 (COM(2011) 244 Final.'

78. Anticipated by, e.g., C.W. Backes and H.F.M.W van Rijswick, 'Ground Breaking Landmark Case on Environmental Quality Standards? The Consequences of the CJEU "Weser-Judgment” (C-461/13) for Water Policy and Law and Quality Standards in EU Environmental Law' (2015) 12 Journal for European Environmental \& Planning Law 363.

79. E. Korkea-aho, 'Watering Down the Court of Justice? The Dynamics between Network Implementation and Article 258 TFEU Litigation' (2014) 20 European Law Journal 649.

80. See Winter et al., above n. 8 . 
developments of the directives that it bases its definitions on, such as the WFD. When the ECJ clarified the WFD objectives in Weser, down to the level of quality elements, the judgment resulted in consequences for the interpretation of other quality standards and 'stand still' clauses, ${ }^{81}$ such as the ELD definition and threshold of water damage. By giving substance to the WFD framework, the ECJ also shaped other adjacent directives. ${ }^{82}$ Here the ELD stands out as it bases its definition on how the WFD defines its main objectives.

In Article 2(1)(b)(i), the ELD defines 'water damage' as any damage that significantly and adversely affects the ecological, chemical, quantitative status or ecological potential, as defined in WFD. This is a clear reference to the normative definitions of WFD Annex V, as this is where the WFD clarifies the ecological, chemical, quantitative status or ecological potential of a body of water. One of the outcomes of Weser is that not only did the ECJ clarify what the WFD assessment of a body of water must refer to, but also the assessment of 'water damage'. Therefore, the normative definitions of Annex V explains the simplification and assessment of aquatic biodiversity under both the WFD and ELD.

As the ELD and WFD overlap and both have a threshold objective, it is important that the conceptualisation of 'water damage' is separated from WFD objectives, such as non-deterioration. This gives Member States an area of discretion in which to address the deterioration of bodies of water according to the WFD; when deterioration is significant, they can turn to the ELD framework. Acknowledging this, the suggestion is that under the ELD, 'water damage' is significant, and results in measures for achieving baseline conditions under the following circumstances:

- when all the quality elements used to classify a body of water, according to Annex V, deteriorate by one class;

- when a body of water is affected by deterioration that results in a class change for the biological quality elements not in the lowest class, and a measurable change in the quality element in a lowest class; and

- when all the biological quality elements in a body of water in a lowest class deteriorate measurably and the deterioration of that body of water compromises the achievement of WFD objectives for other bodies of water.

As the analysis in this article shows, Weser is a good reference to determine when a 'water damage' incident take place. The ECJ has succeeded, knowingly or unknowingly, in securing a coherent approach between the ELD and WFD. ${ }^{83}$

\section{Declaration of conflicting interests}

The author(s) declared no potential conflicts of interest with respect to the research, authorship, and/or publication of this article.

\section{Funding}

The author(s) disclosed receipt of the following financial support for the research, authorship, and/or publication of this article: The author received financial support from the Swedish Research Council, grant number 2015-01437.

81. See Backes and van Rijswick, above n. 79 .

82. This has been pointed out in other areas of EU law, see Sonia Morano-Foadi and Stelios Andreadakis, 'Reflections on the Architecture of the EU after the Treaty of Lisbon: The European Judicial Approach to Fundamental Rights' 17 European Law Journal 595.

83. Pointed out by M.P. Maduro, 'Interpreting European Law: Judicial Adjudication in a Context of Constitutional Pluralism' (2007) 1 European Journal of Legal Studies 1. 